\title{
Risk Assessment and Decision-Making under Uncertainty in Tunnel and Underground Engineering
}

\author{
Yuanpu Xia ${ }^{1} \mathbb{C}^{\mathbb{D}}$, Ziming Xiong ${ }^{1,2, *}$, Xin Dong ${ }^{1}$ and Hao Lu ${ }^{1}$ \\ 1 State Key Laboratory of Disaster Prevention \& Mitigation of Explosion \& Impact, \\ The Army Engineering University of PLA, Nanjing 210007, China; xiayuanpu123@163.com (Y.X.); \\ 13401978351@163.com (X.D.); lh829829@163.com (H.L.) \\ 2 School of Mechanical Engineering, Nanjing University of Science and Technology, Nanjing 210094, China \\ * Correspondence: xzm9992311@163.com
}

Received: 31 August 2017; Accepted: 16 October 2017; Published: 18 October 2017

\begin{abstract}
The impact of uncertainty on risk assessment and decision-making is increasingly being prioritized, especially for large geotechnical projects such as tunnels, where uncertainty is often the main source of risk. Epistemic uncertainty, which can be reduced, is the focus of attention. In this study, the existing entropy-risk decision model is first discussed and analyzed, and its deficiencies are improved upon and overcome. Then, this study addresses the fact that existing studies only consider parameter uncertainty and ignore the influence of the model uncertainty. Here, focus is on the issue of model uncertainty and differences in risk consciousness with different decision-makers. The utility theory is introduced in the model. Finally, a risk decision model is proposed based on the sensitivity analysis and the tolerance cost, which can improve decision-making efficiency. This research can provide guidance or reference for the evaluation and decision-making of complex systems engineering problems, and indicate a direction for further research of risk assessment and decision-making issues.
\end{abstract}

Keywords: uncertainty; risk assessment; decision-making; entropy; sensitivity analysis; tunnel

\section{Introduction}

Tunnel and underground engineering are examples of large-scale complex systems engineering, and various uncertainties may be involved during construction. Particularly, in examining the geological conditions of complex areas such as karst development areas, various safety accidents such as collapses [1] and water inrushes [2] can easily be triggered, which will affect all parties involved as well as those not directly involved in the project [3]. Risk assessment has been increasingly valued and regarded as a guarantee for the safe and smooth construction of large engineering projects $[4,5]$. Risk assessment is an important part of risk management, which is a tool designed to support all aspects of decision-making from the beginning to the end of a process. Various risk assessment tools have been widely used in tunnel and underground engineering, including event tree analysis [6], fault tree analysis [7], probabilistic risk analysis [8,9], the analytical hierarchy process [10], multicriteria verbal analysis [11], Grey systems [12], Bayesian networks [13], fuzzy sets [14], and Monte Carlo simulations $[15,16]$.

Probabilistic risk analysis (PRA) is the most widely used method of quantitative risk analysis in geotechnical engineering $[17,18]$. However, in engineering practice, scholars have gradually realized that insufficient information is a major problem in tunnel and underground engineering, and this lack of information cannot support precise probability. Therefore, an imprecise probability is considered more in line with the actual state of a project $[19,20]$. In addition, with modern developments in science and technology, artificial intelligence methods such as Geographic Information System (GIS) [21] and risk analysis software [22] have also been applied to tunnel and underground engineering. 
The large-scale application of these risk assessment methods in geotechnical engineering provides a strong theoretical basis for the risk assessment and management of tunnel and underground engineering, and plays a significant role in reducing the number of safety accidents and controlling construction costs. However, most of the above research methods mainly consider risk assessment based on the factors of consequence and possibility [23], that is, the classical risk description method: $R=P \times C$. However, many scholars began to question the rationality of the above definition of risk. Probability is the most common measure of uncertainty used for risk assessment. Other measures are also used, such as possibility theory and evidence theory, especially when faced with a lack of information [24-27].

Aven proposed that using $(C, U)$ instead of $(C, P)$, where " $U$ " indicates uncertainty, should be more reasonable [28]. In 2015, the Society for Risk Analysis (SRA) stated that it was necessary to modify the traditional definition of risk. The risk description associated with the definition of $(C, U)$ can be $\left(C^{\prime}, Q, K\right)$, where $C^{\prime}$ denotes specified consequences; $Q$ is a measure of uncertainty such as probability, imprecise probability, or boundary probability; and $\mathrm{K}$ can be considered as the background knowledge on which the specifications and assignments of $C^{\prime}$ and $Q$ are based $[29,30]$. For the new definition of risk, we place special emphasis on the role of background knowledge in risk assessment. We now provide further explanation by enumerating a simple example similar to that in [31].

In Table 1, although the risk value of the two sections is the same, the degree of uncertainty of background knowledge supporting the risk value is different. If the decision-maker is only informed of the risk value, the same risk control measures may be taken by the decision-maker, but this is obviously unreasonable. For section a, owing to the large degree of uncertainty, decision-makers may demand measures to reduce the uncertainty. For complex systems engineering such as tunnels and oil and gas pipelines, the initial information is not always sufficient. Thus, measures should be taken to reduce the impact of uncertainty on the risk assessment [32,33]. At present, there are few studies that provide theoretical guidance for taking measures to reduce the uncertainty. Based on the principle that information entropy can quantify the uncertainty, and drawing on the idea from the expected utility-entropy model [34,35], the entropy-hazard risk assessment model has been proposed [31]. Although the model still has some shortcomings, which will be discussed in the second section, this represents significant progress in risk theory research and can provide a good foundation for follow-up risk assessment research.

Table 1. Risk assessment results of different sections in a tunnel.

\begin{tabular}{cccccc}
\hline & \multicolumn{2}{c}{ Risk Factors } & \multicolumn{3}{c}{ Risk Value } \\
\hline & $\mathbf{X}_{\mathbf{1}}$ & $\mathbf{X}_{\mathbf{2}}$ & Probability & Outcome & Risk Value \\
\hline Section a of a tunnel & $(0,2)$ & 1 & 0.5 & $\mathrm{C}$ & $0.5 \mathrm{C}$ \\
Section b of a tunnel & $(0.9,1.1)$ & 1 & 0.5 & $\mathrm{C}$ & $0.5 \mathrm{C}$ \\
\hline
\end{tabular}

The purpose of a risk assessment is to provide favorable and reliable information for decision-making. The assessment should mainly include objective judgments of consequences and related uncertainties based on existing information, analyze the necessity of reducing uncertainty, and consider the risk assessment phase from the perspective of decision-making [36-38]. Currently, decision-making under risk is a basic issue in the research of risk analysis. Many scholars such as Tom [39] and Karagoz [40] have discussed the issue. Yang [35] and Gao [41] proposed the expected utility-entropy (EU-E) decision-making model under risk, and successfully applied it to different fields. However, there are still some deficiencies in the model, which can be referred to in [31] and [42].

For complex system engineering such as mountain tunnels, the security issues are generally more complex, multiple requirements should be considered when make decisions related to these issues, which belong to multiple criteria decision-making (MCDM) [43]. For example, for an appropriate risk control scheme, factors such as cost, time, environment, reliability, etc. may be considered. In recent years, the study of multi-criteria decision making is becoming more and more popular 
in civil engineering [44]. For example, Antucheviciene et al. [45] have systematically summarized and analyzed the research status of MCDM in civil engineering. The research: (1) Emphasizes the necessity of considering uncertainty in the decision-making process, and proposes describing the uncertainty with fuzzy or probabilistic methods, alone or in combination; (2) Emphasizes the importance of sensitivity analysis in multi-objective decision making and proposes a specific analysis model; (3) Considers the impact of risk on decision criteria, and proposes specific risk measurement methods. The relationships between uncertainty, risk, and decision criteria such as cost are also the focus of this paper. Therefore, the above research achievements provide a strong foundation for this study.

From the above analysis we can see that the research on risk decision making has made important progress both in theory and for engineering applications. However, the above studies do not significantly consider risk assessment issues from the perspective of favorable decision-making, nor do they clearly identify the linkages and differences between risk analysts and decision-makers. Some researchers even think that evaluation and decision-making are performed by the same person or team. However, in tunnel and underground engineering, risk assessment and risk decision-making typically belong to different individuals or teams, and sometimes the same evaluation results will be submitted to different decision-makers simultaneously.

The relationship between analysts and decision-makers increases the complexity of the risk assessment of tunnel and underground engineering [46,47]. To this end, Aven [48] proposed a two-stage risk assessment method that defines the respective responsibilities of analysts and decision-makers. They put forward the concept of strength of knowledge (SOK) to judge the background knowledge. The lower the uncertainty, the greater the need for information, and the higher the SOK is. This principle is exactly the same as the entropy value that quantifies the information uncertainty, but the entropy may be more specific and more intuitive.

Based on the above research, we will continue to use the concept of information entropy $[49,50]$. The factors in the risk assessment stage that may influence decision-making will be analyzed. These factors include parameter uncertainty, model uncertainty, necessity hypothesis analysis, and sensitivity analysis. We believe that the above analysis can provide decision-makers with rich and beneficial information, and not just the evaluation results $(C, P)$.

This paper is organized as follows. In Section 2, we mainly discuss and perfect the related issues in the literature [31] regarding the influence of the parameter uncertainty and ways to reduce the uncertainty. Section 3 introduces the influence of model uncertainty and a related hypothesis of the risk assessment results, and quantifies the relevant impact. In Section 4, the risk assessment and decision-making problems of Yuelongmen tunnel has been analyzed and discussed based on the improved model, and the rationality and engineering adaptability of the model are verified. Finally, Section 5 provides our conclusions.

\section{Parameter Uncertainty Analysis}

It is important to recognize that in geotechnical engineering, including tunnel and underground engineering, many of the risk sources arise from geotechnical uncertainty [18]. Owing to insufficient information, there will be uncertainty in the model parameters. Parametric uncertainty is one of the most common epistemic uncertainties, and can be reduced by collecting more information. Several theories such as interval analysis [51], possibility theory [52], evidence theory [53], and Bayesian probability theory [54] have been used to represent the uncertainty. However, these are focused only on solving the problems of hazards, that is, $(C, Q)$, and ignoring the uncertainty of the background knowledge $(\mathrm{K})$, which is important for decision-making as discussed in the introduction. The model of entropy-hazard could provide theoretical guidance to reduce uncertainty. However, we find that some problems still need to be improved upon for the model to be perfected. Thus, this section will mainly discuss the parameter uncertainty based on [31].

From $(C, Q, K)$, we know that risk is related not only to uncertainty but also to hazards. Changes in uncertainty, especially changes in parameter uncertainty, can cause a hazard change 
in the risk assessment model. The dynamic relationship between the uncertainty and hazard makes the decision-making process more complex. Risk control measures are mainly considered from two aspects: reducing the uncertainty and reducing the hazard. However, different combinations of uncertainties and hazards will lead to different choices. The different combinations are as follow.

Table 2 lists six common combinations. Obviously, for the 2nd and 6th situations, no risk control measures will be taken, and in the 5th case we will choose measures to reduce the hazard. In the 3rd scenario, we must first reduce the uncertainty. The key question is how to make decisions in the 1st and 4th situations. Dong et al. [31] think that for the first cases, owing to small hazards despite the large uncertainty, there is no need for measures to reduce uncertainty. By contrast, in the 4th case, because of a large hazard, measures should be taken to reduce uncertainty.

Table 2. Combinations of uncertainties and hazards.

\begin{tabular}{cccccc}
\hline Serial Number & $\mathbf{U}$ & $\boldsymbol{R}_{\mathbf{1}}$ & Serial Number & $\mathbf{U}$ & $\boldsymbol{R}_{\mathbf{1}}$ \\
\hline 1 & Large & Small & 4 & Small & Large \\
2 & Small & Small & 5 & 0 & Large \\
3 & Large & Large & 6 & 0 & Small \\
\hline
\end{tabular}

The degree of uncertainty of the parameters can affect the value of the hazard $\left(R_{1}\right)$. In the first case, if measures are taken to reduce the uncertainty, the value of the hazard may be changed from small to large, that is to say, the risk will change dramatically. It is obviously unreasonable to take no actions simply because the initial hazard is small. In the fourth case, in tunnel construction, people may be more inclined to take measures to reduce the hazard rather than reduce the uncertainty.

In view of the above situations, there is no strict theory to guide a choice. In addition, the decision-making process may also be affected by the risk attitude of the decision-makers. Based on the above analysis, we believe that it is more reasonable to consider the effects of uncertainties and hazards simultaneously.

The above is only a qualitative analysis. The following will be further illustrated by specific examples. The formula is $y=\frac{x_{1}}{x_{2}}-1$. If $y \leq 0$, a risk incident does not occur, while if $y>0$, a risk incident does occur.

In Table 3, we list as many possible scenarios as possible. The first six belong to the situations corresponding to Table 2 . Taking the first cases as the initial values, after taking measures to reduce the uncertainty, there may be two cases, 2 and 4, and the risk values of the two are very different. Since risk control measures correspond to risk levels, if measures are taken to reduce the hazard directly for the first case, the effect of reducing the risks will not be obvious, and may even mislead the decision-maker and increase the risk of decision-making. Thus, the tolerance cost $T_{H}^{\prime}$ is related to the uncertainty and hazard, and the following formula may be more reasonable:

$$
T_{H}^{\prime}=\alpha H R_{1}
$$

The mean of $\alpha$ is the same as that in [31]. According to the above analysis, after taking measures to reduce the uncertainty, the value of the hazard is likely to change. Sometimes the values of $R_{1}$ and $R_{1}^{\prime}$ can be changed significantly. Therefore, we think that the hazard value takes the larger of $R_{1}$ or $R_{1}^{\prime}$.

$$
T_{H}^{\prime}=\alpha H \max \left(R_{1}, R_{1}^{\prime}\right)
$$

In the 7th scenario, the uncertainty and hazard are large, but it does not make sense to take measures to reduce the uncertainty, and the formula fails to reflect the problem. Therefore, use of the above formula is also conditional, that is, $H\left(R_{1}\right) \neq 0$. In addition, the tolerance cost $T_{H}^{\prime}$ is also affected by the decision-making effect, that is, the effect obtained after measures are taken to reduce the uncertainty. The better the effect, the more people willing to take this measure. We can use the reduced ratio of uncertainty to show the effect: $e=\frac{H-H^{\prime}}{H}$ so that 


$$
T_{H}^{\prime}=\alpha H\left(\frac{H-H^{\prime}}{H}\right) \max \left(R_{1}, R_{1}^{\prime}\right)
$$

In [31], uncertainty is expressed by the risk incident $(\mathrm{A})$ or risk level $\left(R_{1}\right)$. However, if the value of the hazard remains unchanged after measures are taken (such as 3 and 4, or 9 and 10 in Table 3), the tolerance value $T_{H}^{\prime}$ will be 0 , which is obviously unreasonable. Let the third case be the initial value and the fourth case the value after measures are taken. We find that it is necessary to take measures to reduce the uncertainty, and the formula in [31] cannot solve the problem. Therefore, in order to avoid the above problem, we believe that the best decision-making effect $(e)$ should be chosen. The formula we recommend is as follows:

$$
T_{H}^{\prime}=\alpha H_{\max } e_{\max } \cdot \max \left(R_{1}, R_{1}^{\prime}\right)
$$

where $H_{\max }=\max \left(H_{x}, H_{A}, H_{Q}, H_{R_{1}}\right)$ and $e_{\max }=\max \left(e_{x}, e_{A}, e_{Q}, e_{R_{1}}\right)$. The meanings of the symbols in the formula are the same as in [31]. The abovementioned improved entropy-risk model is used to control or deal with the uncertainty of the parameters so that the consequences of the uncertainty are reduced to an acceptable range and provide favorable and reliable information for subsequent risk decisions. Next, the impact of the model uncertainty on risk assessment and decision-making will be discussed.

Table 3. Risk factor values and risk values $(R=Q \times C)$.

\begin{tabular}{cccccc}
\hline Serial Number & \multicolumn{2}{c}{ Risk Factors } & \multicolumn{3}{c}{ Risk Value } \\
\hline & $\mathbf{X}_{\mathbf{1}}$ & $\mathbf{X}_{\mathbf{2}}$ & Probability & Outcome & Risk Value \\
\hline 1 & $(4,14)$ & 12 & 0.2 & $\mathrm{C}$ & $0.2 \mathrm{C}$ \\
2 & $(11.2,12.2)$ & 12 & 0.2 & $\mathrm{C}$ & $0.2 \mathrm{C}$ \\
3 & $(8,28)$ & 12 & 0.8 & $\mathrm{C}$ & $0.8 \mathrm{C}$ \\
4 & $(11.8,12.8)$ & 12 & 0.8 & $\mathrm{C}$ & $0.8 \mathrm{C}$ \\
5 & 13 & 12 & 1 & $\mathrm{C}$ & $\mathrm{C}$ \\
6 & 11 & 12 & 0 & 0 & 0 \\
7 & $(13,20)$ & 12 & 1 & $\mathrm{C}$ & $\mathrm{C}$ \\
8 & $(2,11)$ & 12 & 0 & 0 & 0 \\
9 & $(11.6,12.4)$ & 12 & 0.5 & $\mathrm{C}$ & $0.5 \mathrm{C}$ \\
10 & $(2,22)$ & 12 & 0.5 & $\mathrm{C}$ & $0.5 \mathrm{C}$ \\
\hline
\end{tabular}

\section{Model Uncertainty Analysis}

Epistemic uncertainty includes parameter uncertainty and model uncertainty [55]. Parameter uncertainties are mainly a result of insufficient data. Model uncertainties include numerical solution errors that arise from the methodology adopted in solving the model equations and form errors that arise owing to assumptions and simplifications made in the development of a model [56]. At present, the main concern in the geotechnical engineering field is the influence of parameter uncertainty, while ignoring the influence of model uncertainty. Because of the complexity of risk assessment in tunnel and underground engineering, the evaluation model may not fully reflect the mechanism of the risk incident. It is necessary to consider factors such as cost and time in the calculation so that the model uncertainty may have a greater impact on the assessment results. In the previous section, we discussed the decision problem under parameter uncertainty. In order to facilitate the subsequent calculations, this section assumes that the parameter uncertainty after taking the measure is negligible with regard to the evaluation result.

Models are built to explain real-world phenomena and frequently involve assumptions, simplifications, and generalizations. Model uncertainty represents the inability of these models to accurately represent the true physical behavior of the system [57]. Suppose there is a limit state function that considers in one case and does not consider in the other case, the effect of model uncertainty:

$$
y(x)=\left(x_{1}, x_{2}, \cdots, x_{n}\right)+\varepsilon_{m}(x)
$$




$$
y(x)=\left(x_{1}, x_{2}, \cdots, x_{n}\right)
$$

where $x_{i}(i=1,2, \cdots, n)$ are the independent model parameters, $\varepsilon_{m}(x)=\varepsilon_{s e}(x)+\varepsilon_{m f}(x)$, and $\varepsilon_{s e}(x)$ represents the surrogate model error, which is the main form of the numerical solution errors and. $\varepsilon_{m f}(x)$ represents the model form errors.

Nannapaneni and Mahadevan proposed two methods based on the First-Order Reliability Methods (FORM) approach and a single-loop Monte Carlo sampling approach to deal with the risk assessment that involves model uncertainty. Detailed processing methods are presented in [57-59]. We can quantify the impact of the model uncertainty on a risk assessment model by assessing the uncertainty of the results, and entropy is a suitable method for quantifying the uncertainty. Let $H\left(y, \varepsilon_{m}\right)$ and $H(y)$ represent the average degree of uncertainty that considers and does not consider the impact of model uncertainty, respectively.

Risk analysts should quantify the impact of model uncertainties and inform decision-makers of relevant assessment information. Then, decision-makers need to consider whether to reduce the impact of the model uncertainties first, or to take measures directly to reduce the hazard. Because different decision-makers may have different factors to consider, combined with differences in background and environment, this may result in different decision-making for the same risk incident $[60,61]$. In the second section, since the decision is made by a risk analyst, the influence of subjective factors cannot be considered, but this section involves different decision-makers using the information provided by analysts to make decisions. Therefore, it may be more reasonable to consider the subjective factor of the decision-makers when determining tolerance costs $T_{H}^{\prime}$. The concept of utility can be successfully applied to quantify the risk preferences of decision-makers [62], such as the attitude toward economic loss, cost, time, and environmental impacts. Figure 1 shows a utility curve that reflects different risk attitudes of decision-makers: risk aversion, risk neutral, and risk seeking.

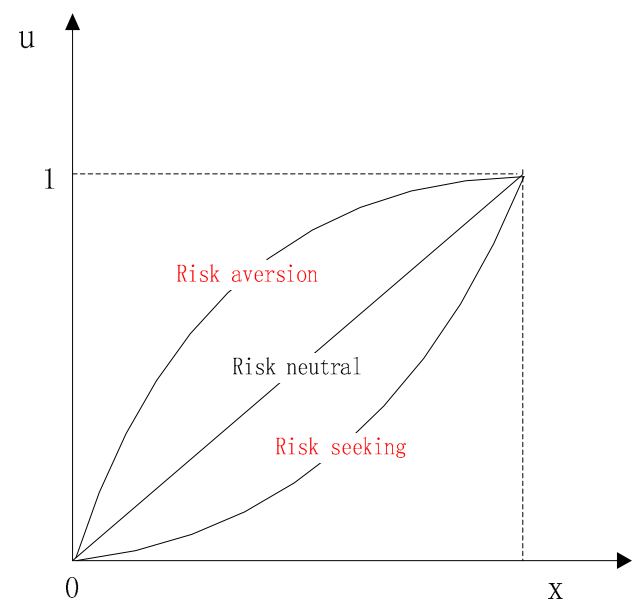

Figure 1. Utility curves for different decision-makers.

Determining the utility function is a challenging task. This has not been sufficiently studied in the civil engineering field as yet $[1,63]$. A utility function can be determined by direct questioning, contrast questioning, the probability equivalent method, or analytic function approximation [64]. The utility function can take the following forms:

Linear function : $u(x)=c_{1}+a_{1}\left(x-c_{2}\right)$

Exponential function : $u(x)=c_{1}+a_{1}\left(1-e^{a_{2}\left(x-c_{2}\right)}\right)$

Power function : $u(x)=a_{1}+a_{2}\left[c_{1}\left(x-a_{3}\right)\right]^{a_{4}}$

Logarithmic function : $u(x)=c_{1}+a_{1} \log \left(c_{3} x-c_{2}\right)$ 
where $a_{1}, a_{2}, a_{3}, a_{4}$ and $c_{1}, c_{2}, c_{3}$ are constants, and $x$ is an independent variable. According to the specific risk decision-making scenarios, $a_{1}, a_{2}, a_{3}, a_{4}$ can be determined. At present, the power function is one of the most commonly used. Thus, in this paper, we choose a power function as the utility function.

$$
u(x)=a_{1}\left(x-c_{1}\right)^{a_{2}}+c_{2}
$$

Through the above analysis, we can obtain a tolerance cost model considering the risk attitude.

$$
\begin{gathered}
u\left(T_{H}^{\prime}\right)=a_{1}\left(T_{H}^{\prime}-c_{1}\right)^{c_{2}}+a_{2} \\
T_{H}^{\prime}=\alpha H\left(y, \varepsilon_{m}\right) \frac{H\left(y, \varepsilon_{m}\right)-H(y)}{H\left(y, \varepsilon_{m}\right)} R_{1}
\end{gathered}
$$

where $\alpha$ and $R_{1}$ are the same as in Section 2. If the decision-maker is risk averse, the tolerance cost will increase; and if the decision-maker is risk seeking, the tolerance cost will decrease. If $T_{H} \leq u\left(T_{H}^{\prime}\right)$, measures should be taken to reduce the model uncertainty. Then, decision-makers need to choose the measure that is most favorable toward reducing the model uncertainty.

In the field of risk control, the available resources should always be focused on the uncertain variables with a high effect on the output response. Because there are two types of model uncertainties, it is not necessary to reduce the overall model uncertainties if the one that has the most impact on the risk assessment results is reduced to an acceptable range, and the analysis is considered to be necessary in terms of economics and time. Therefore, the sensitivity of the two factors can be analyzed first.

Sensitivity analysis is an efficient tool to identify the contribution of uncertain input variables. This is generally grouped into two classes: local sensitivity analysis and global sensitivity analysis [65]. The drawback of local sensitivity analysis is its dependence on the choice of reference point. Global sensitivity analysis is more widely used, and many global sensitivity methods have been proposed, including variance-based sensitivity methods [66], Kullback-Liebler divergence methods [67], and screening methods [68]. In recent years, the global sensitivity method based on entropy has received more and more attention [69,70]. Therefore, this paper proposes an entropy-based sensitivity analysis to determine what measures are taken to reduce the model uncertainty. The formula is as follows:

$$
\begin{aligned}
\eta_{s e} & =\frac{H\left(y, \varepsilon_{m}\right)-H\left(y \mid \varepsilon_{s e}\right)}{H\left(y, \varepsilon_{m}\right)} \\
\eta_{m f} & =\frac{H\left(y, \varepsilon_{m}\right)-H\left(y \mid \varepsilon_{m f}\right)}{H\left(y, \varepsilon_{m}\right)}
\end{aligned}
$$

where $H\left(y \mid \varepsilon_{s e}\right)$ and $H\left(y \mid \varepsilon_{s e}\right)$ indicate the degree of uncertainty of the model output without considering $\varepsilon_{s e}$ or $\varepsilon_{m f}$, respectively. The sensitivity index $\eta$ can be taken as a measure of importance of the input variables in the evaluation model. If $T_{H}>u\left(T_{H}^{\prime}\right)$, measures should be taken to reduce the hazard $\left(R_{1}\right)$.

Different participants are involved in the construction process of tunnel and underground engineering, such as investors, contractors, supervisors, and in some cases, government-related entities [1,71]. Therefore, when considering measures to reduce the hazard, because the interests of different participants involved are not exactly the same, the problems considered are not exactly the same. A decision-maker is an individual or group who can bear the consequences of decision-making. At present, the differences and relationships between a risk analyst and a decision-maker are not very clear in the field of risk control of geotechnical engineering, but in the research field of risk theory, Aven et al. [48] clearly delineated the responsibilities of risk analysts and decision-makers in the process of risk assessment and control. Therefore, for some high-risk control problems, risk analysts need only to provide reliable, objective, and favorable risk decision-making information. The final risk control program should be determined by the different participants together. 
Based on the above analysis, risk analysts can provide information for decision-making, including hazards $\left(R_{1}\right)$, risk levels, sensitivity analyses of input parameters, and recommendations related to risk control measures. Decision-makers can determine the severity of the risk through hazard and risk levels. Then, using sensitivity analysis, they can quickly identify the factors that have the greatest impact on risk assessment, and focus on measures to control risk based on these factors. Last, the introduction of cost tolerance $T_{H}^{\prime}$ or $u\left(T_{H}^{\prime}\right)$ can further determine what measures are most economically feasible. The specific risk assessment and decision-making process is shown in Figure 2 .

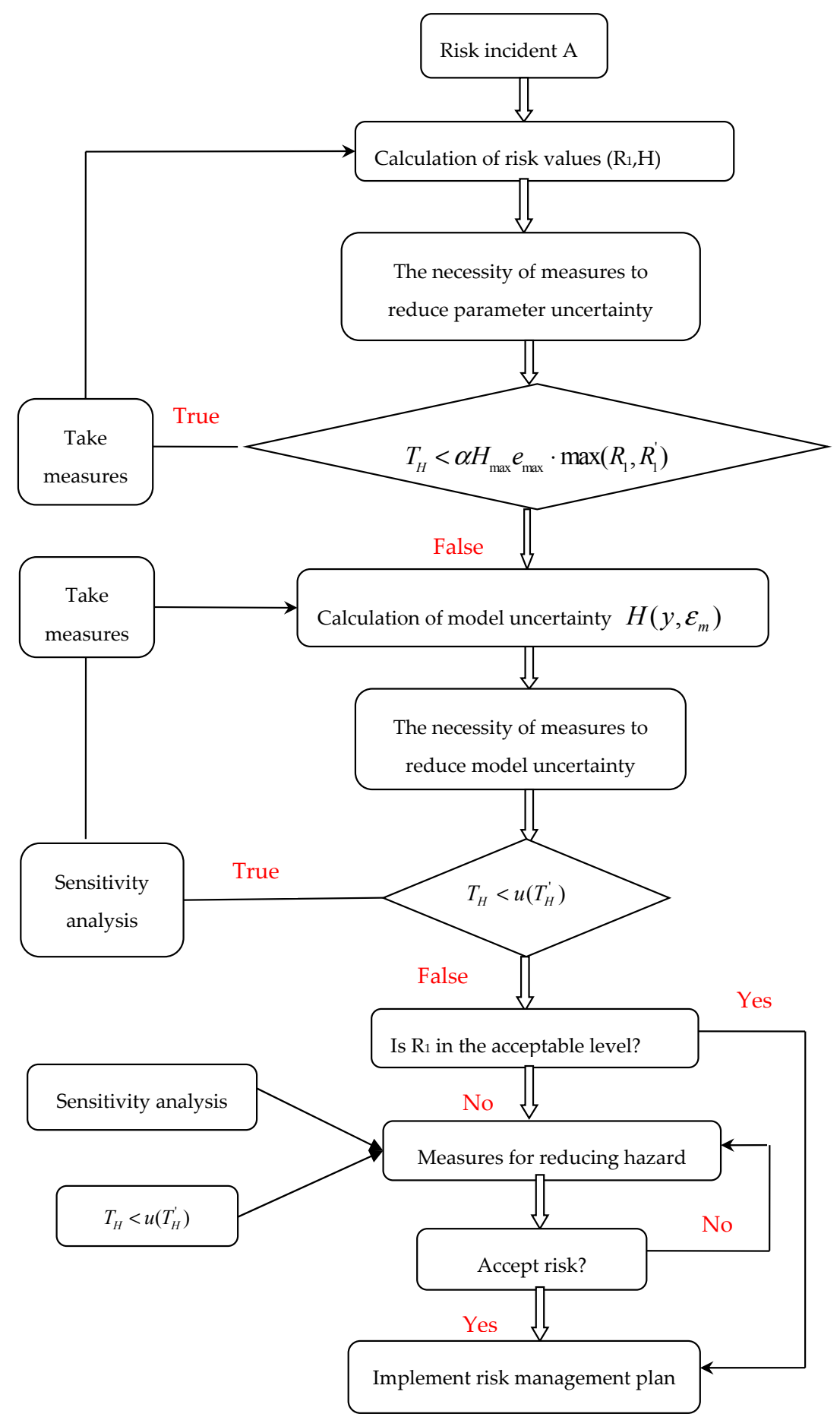

Figure 2. Risk assessment and decision-making process. 


\section{Case Analysis}

\subsection{Engineering Background}

The geological structure is complex, and the karst is widely distributed in the western mountain area of China. The tunnels in this area are characterized as deeply buried, long hole lines, high stress, strong karst, and high water pressure [72]. These characteristics facilitate water inrush and other geological disasters during tunnel construction. For example, the Malujing tunnel shown in Figure 3 has undergone serious water inrush disaster and has caused serious losses and adverse social impact. Water inrush is a major challenge in the construction of tunnels in Southwest China.
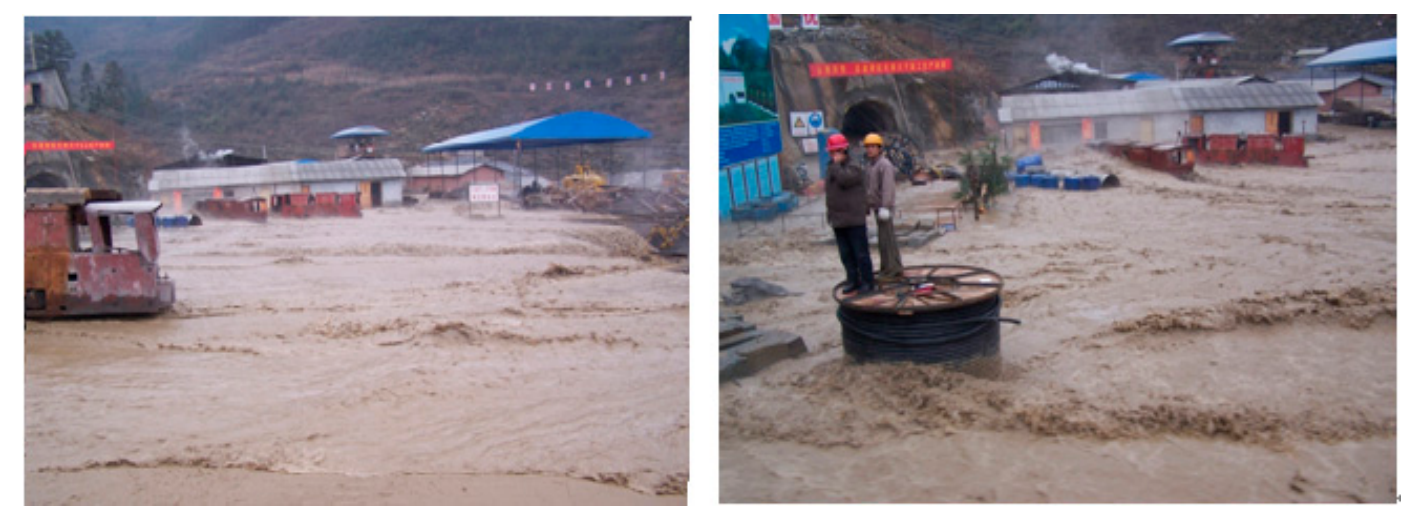

Figure 3. An accident due to water inrush in the Malujing tunnel of Yiwan railway.

The research background of this paper is the Yuelongmen tunnel of Chengdu-Lanzhou railway (Figure 4). The Yuelongmen tunnel is a control project for the railway which has a length of approximately $20 \mathrm{~km}$, and the maximum depth is $1445.5 \mathrm{~m}$. The tunnel is located in the core area of the Wenchuan earthquake, and small earthquakes still occur frequently. The tunnel passes through the Longmen Mountain Fault Zone, and karst is present in some areas. The engineering geology and hydrogeology is complex and belongs to high risk tunnel project. The hydrogeological map of the tunnel area is shown in Figure 5.

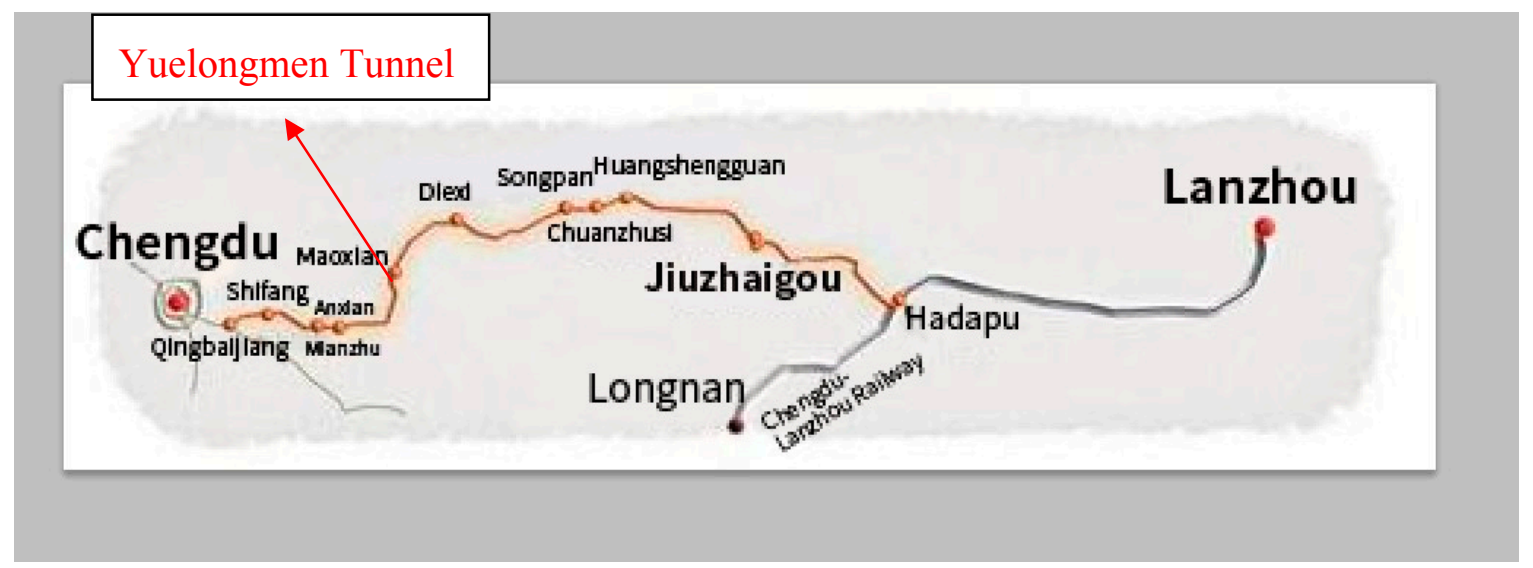

Figure 4. Azimuth map of Yuelongmen tunnel.

The tunnel adopts the method of using horizontal and inclined shafts to work together from multiple directions, thus speeding up construction of the tunnel. Through the actual investigation (Figure 6) and consulting relevant materials, we find that No. 3 inclined shaft has the following characteristics: 
1. The construction site is narrow and has inconvenient traffic.

2. Karst development includes broken rock and enriched water content.

3. It has an inclined well with anti-slope construction that has unfavorable drainage.

4. The construction of the inclined shaft caused the nearby river to pour into the mountain.

5. The No. 3 inclined shaft resulted from a design change, where the geological data was not detailed. The area orientation of the No. 3 inclined shaft is shown in Figure 7.

These characteristics cause the No. 3 inclined shaft to face a great risk of water inrush. Thus, the No. 3 inclined shaft represents a good example as the research object. Here the typical sections of XJ3K1 + 465 through XJ3K1 + 425 are selected for risk decision making related to water inrush.

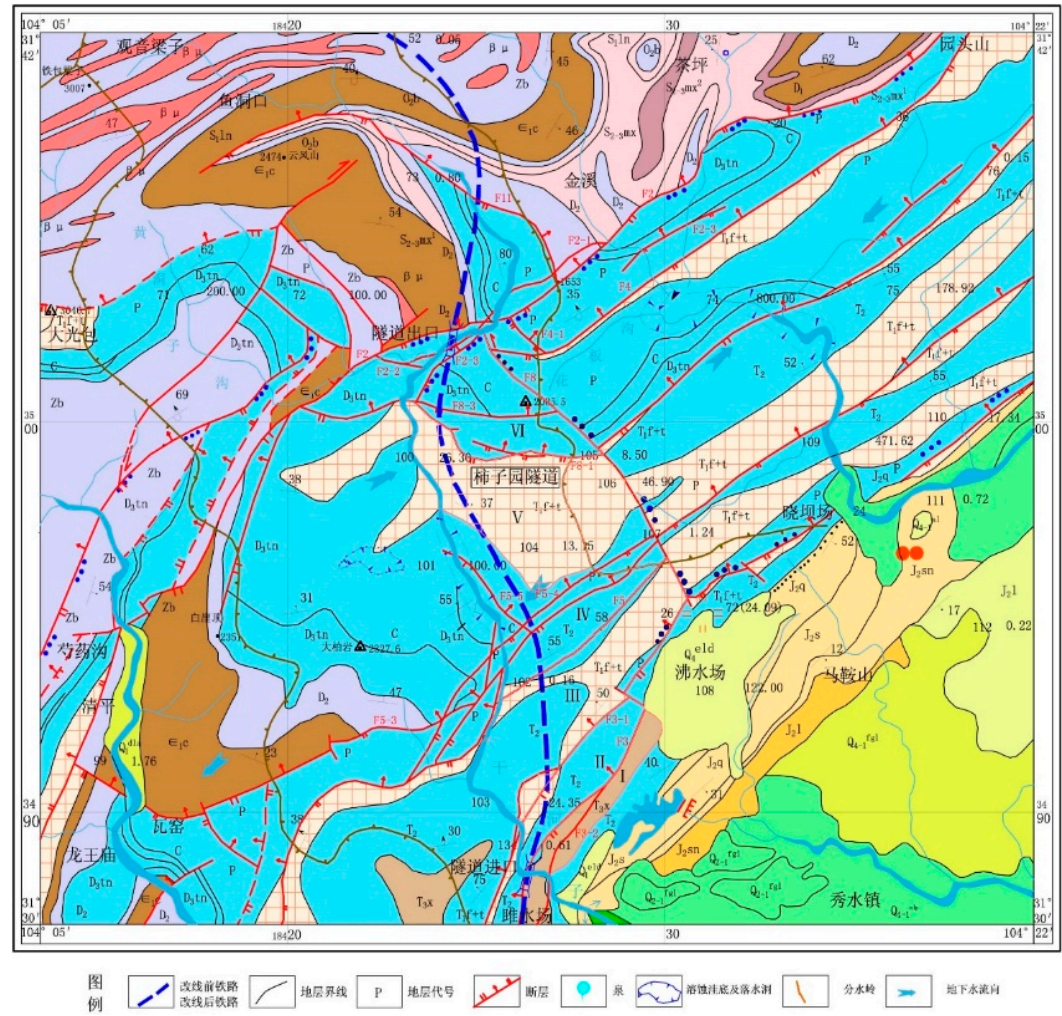

Figure 5. Hydrogeological map of Yuelongmen tunnel.


Figure 6. On-site Investigation of Yuelongmen Tunnel. 


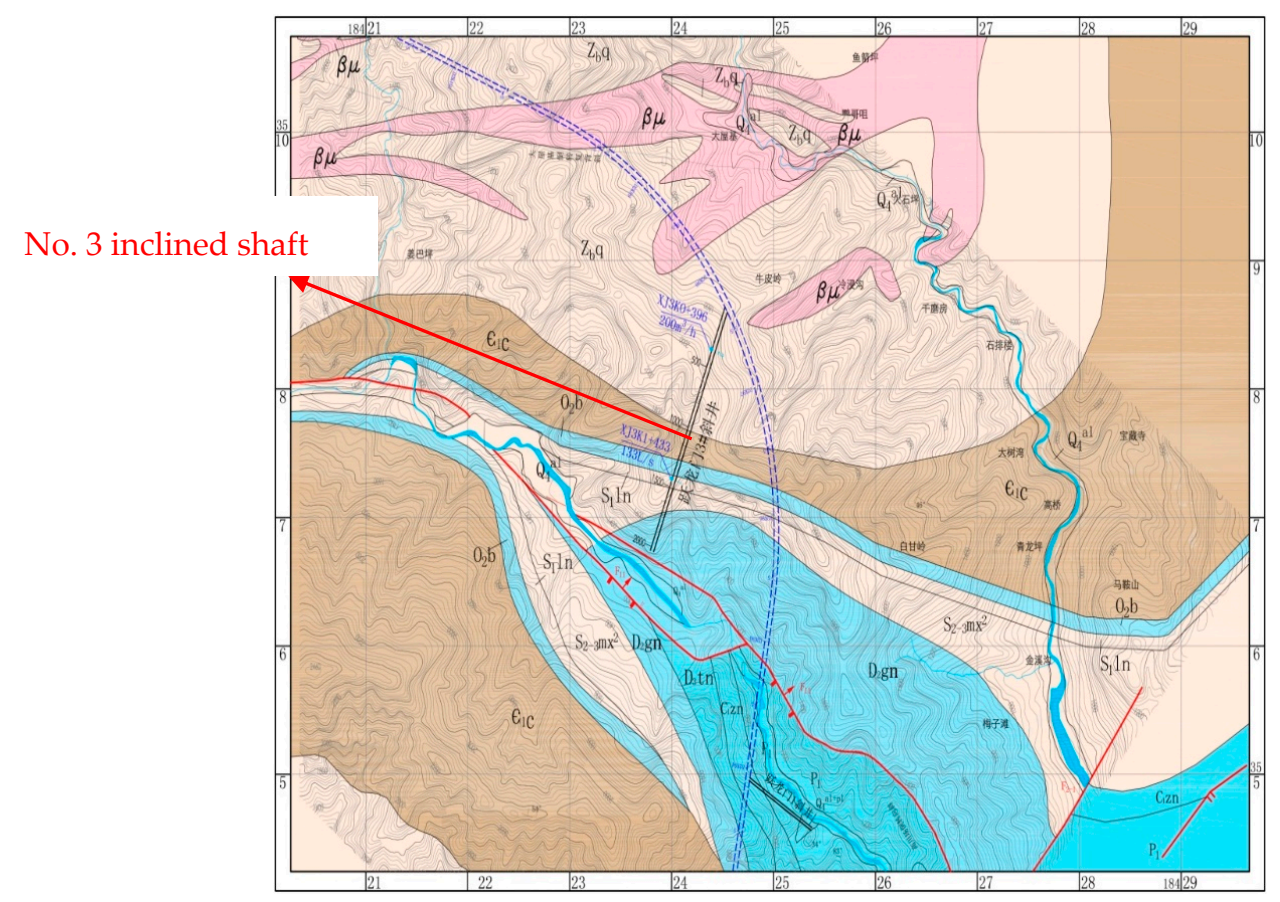

Figure 7. Azimuth map of No. 3 inclined shaft of Longmen tunnel.

\subsection{Engineering Application and Discussion}

For decision making under parameter uncertainty, Ref. [31] has fully elaborated on the problem through theoretical analysis and engineering case application. This section will mainly discuss water inrush in tunnels under model uncertainty. Assume that the risk assessment model of the water inrush is $P(A)=g\left(x_{1}, x_{2}, \cdots, x_{n}\right)$, risk levels are divided into four levels of I, II, III, IV, and I is the highest risk. Firstly, only consider the impact of parameter uncertainty, and the probability of water inrush is $P(A)=0.0234$, which can be obtained by common probabilistic methods, such as Bayesian network, fault tree, etc. Then, the probabilities of second-grade and third-grade risk levels are 0.58 and 0.42 , respectively, and $H\left(R_{1}\right)=0.6803$. Assuming that measures are taken to reduce the parameter uncertainty, and the probability of $P(A)$ is 0.0276 , so that $H\left(R_{1}\right)=0.0901$. The above analysis shows that the parameter uncertainty has a great impact on the risk value of water inrush. After taking measures to reduce the uncertainty of parameters, the degree of uncertainty of the risk value is obviously decreased.

Due to the complexity of geological conditions, the existing knowledge cannot give a very accurate interpretation of the mechanism of water inrush, and different people will have different opinions. For example, with regard to the basic factors that affect water inrush, some believe there are four main factors, some think it is eight, but others think there are more than twelve. In addition, for numerical simulation of water inrush, the calculation result may be different because of the different precisions of mesh generation. The uncertainty of the risk assessment results caused by the above reasons can be considered as the effect of numerical solution errors $\varepsilon_{s e}(x)$ and model form errors $\varepsilon_{m f}(x)$.

The more comprehensively the influence factors are considered and the higher the precision of mesh generation, the relative risk assessment results will be more reasonable. But, it also adds pressure to modeling, time, and economics. Now we analyze the impact of model uncertainty $\varepsilon_{m}$ on water inrush risk. For information regarding the specific calculation method, readers can refer to $[53,54]$. The expected probability is 0.0255 . Obviously, the model uncertainty has a great influence on the evaluation result. The probabilities of second-grade and third-grade risk levels are 0.781 and 0.219 , and $H\left(R_{1}, \varepsilon_{m}\right)=0.5256$. According to experienced experts, the occurrence of water inrush will cause a loss of $2 \times 10^{6} \mathrm{RMB}$. 
According to (13), the cost of the tolerance is $T_{H}^{\prime}=174,200$. Suppose that, according to expert opinion, the cost of taking measures is 180,000 . When decision-makers are risk neutral or risk seeking, that is, $u\left(T_{H}^{\prime}\right)<180,000$, they consider that there is no need to take measures, while a risk conservative decision-maker may consider taking measures. Suppose (12) has the parameters $a_{1}=1.08, a_{2}=2$, $c_{1}=0, c_{2}=1$, the tolerance cost is $u\left(T_{H}^{\prime}\right)=188,138>180,000$, and in this case, decision-makers will consider it necessary to take measures. Obviously, different risk attitudes of decision-makers result in different judgment results.

If measures need to be taken to reduce the model uncertainty, the one with the greatest impact on the output can be determined by the entropy-based global sensitivity analysis method described above. For example, if the calculation shows that $P\left(y, \varepsilon_{s e}\right)=0.0260$, then the probabilities of the second-grade and third-grade risk levels are 0.8289 and 0.1711 , respectively. Similarly, we know that $P\left(y, \varepsilon_{m f}\right)=0.0274$, and the probabilities of the second-grade and third-grade risk levels are 0.9629 and 0.0307 , respectively. Through the calculation of information entropy, we know that $H\left(R_{1} \mid \varepsilon_{s e}\right)=0.4576$, $H\left(R_{1} \mid \varepsilon_{m f}\right)=0.1586$. Sensitivity indicators are available according to (14) and (15). Thus, $\eta_{s e}=0.1284$, $\eta_{m f}=0.6982$. According to the above analysis, the sensitivity index of the model form uncertainty is much larger than the numerical uncertainty, so the first consideration is to take measures to reduce the model form uncertainty. For the model uncertainty of water inrush, it is necessary to consider how to construct the risk assessment model based on the mechanism of water inrush.

If there is no need to take measures to reduce the uncertainty, we instead take measures directly to reduce the hazard. Similarly, first, a sensitivity analysis should be conducted on the input variables, and then the factors with the most impact on the output results should be determined. According to these factors, corresponding risk control measures are adopted. These can reduce the calculation cost and reduce the blindness of the measures, and improve the efficiency of the risk assessment and risk decision-making. Finally, the final measure can be further determined by the tolerance cost $T_{H}^{\prime}$.

\section{Conclusions}

Uncertainty is one of the most important characteristics of geotechnical engineering. Scholars are increasingly focusing on how to deal with uncertainty in the process of risk assessment and risk control, especially regarding epistemic uncertainty. However, owing to the constraints of the traditional concept of risk, there are still many issues in the treatment of uncertainty. The relationship between uncertainty and risk is still relatively vague. Based on the existing research, this paper studied how to deal with uncertainty and how to evaluate and make decisions under uncertainty. The main conclusions are as follows:

(1) Through an analysis of examples, the existing issues in the entropy-hazard risk assessment model are discussed, and corresponding improvement measures are put forward.

(2) Epistemic uncertainty mainly includes parameter uncertainties and model uncertainties, but the existing research focuses primarily on parameter uncertainties. In addition, the influence of model uncertainties is further considered on the basis of parameter uncertainties.

(3) Owing to the difference in risk consciousness between analysts and decision-makers, we discuss the relation and difference between analysts and decision-makers in the process of risk assessment and risk decision-making.

(4) Considering the differences in risk attitudes between different decision-makers, the utility theory is introduced into the tolerance cost model.

(5) For decision-making under model uncertainty, two factors (entropy-based sensitivity analysis and tolerance cost) are considered to improve decision-making efficiency.

Acknowledgments: We are grateful to several anonymous reviewers for providing valuable suggestions for improvement. This work was supported by the National Key Basic Research Program (2013CB036005). The financial support is gratefully acknowledged. 
Author Contributions: Yuanpu Xia conceived, designed, and performed the study. Ziming Xiong and Xin Dong collected and analyzed the example in the paper. Yuanpu Xia and Hao Lu wrote and revised the paper together. The authors have read and approved the final published manuscript.

Conflicts of Interest: The authors declare no conflict of interest.

\section{References}

1. Špačková, O.; Novotná, E.; Šejnoha, M.; Šejnoha, J. Probabilistic models for tunnel construction risk assessment. Adv. Eng. Softw. 2013, 62, 72-84. [CrossRef]

2. Li, S.; Zhou, Z.; Li, L.; Xu, Z.; Zhang, Q.; Shi, S. Risk assessment of water inrush in karst tunnels based on attribute synthetic evaluation system. Tunn. Undergr. Space Technol. 2013, 38, 50-58. [CrossRef]

3. Eskesen, S.D.; Tengborg, P.; Kampmann, J.; Veicherts, T.H. Guidelines for tunnelling risk management: International Tunnelling Association, Working Group No. 2. Tunn. Undergr. Space Technol. 2004, 19, $217-237$. [CrossRef]

4. Einstein, H. Risk and risk analysis in rock engineering. Tunn. Undergr. Space Technol. 1996, 11, 141-155. [CrossRef]

5. Lin, M.L.; Chin, C.T.; Lin, H.D. New Generation Design Codes for Geotechnical Engineering Practice-Taipei 2006: (with CD-ROM); National Taiwan University of Science and Technology: Taipei, Taiwan, 2006.

6. Hong, E.S.; Lee, I.M.; Shin, H.S.; Nam, S.W.; Kong, J.S. Quantitative risk evaluation based on event tree analysis technique: Application to the design of shield TBM. Tunn. Undergr. Space Technol. 2009, 24, 269-277. [CrossRef]

7. Vaurio, J.K. Ideas and developments in importance measures and fault-tree techniques for reliability and risk analysis. Reliab. Eng. Syst. Saf. 2010, 95, 99-107. [CrossRef]

8. Špačková, O.; Šejnoha, J.; Straub, D. Probabilistic assessment of tunnel construction performance based on data. Tunn. Undergr. Space Technol. 2013, 37, 62-78. [CrossRef]

9. Fenton, G.A.; Griffiths, D.V. Risk Assessment in Geotechnical Engineering; John Wiley and Sons, Inc.: New York, NY, USA, 2008.

10. Woo, S.K.; Kim, K.J.; Kim, T.H. The Risk Factor Analysis of Power Line Tunnel Using the AHP Method in Construction Stage. J. Korea Inst. Struct. Maint. Insp. 2013, 17, 122-129. [CrossRef]

11. Ustinovichius, L.; Barvidas, A.; Vishnevskaja, A.; Ashikhmin, I.V. Multicriteria verbal analysis for the decision of construction problems. Technol. Econ. Dev. Econ. 2009, 15, 326-340. [CrossRef]

12. Zavadskas, E.K.; Turskis, Z.; Tamošaitiene, J. Risk assessment of construction projects. J. Civ. Eng. Manag. 2010, 16, 33-46. [CrossRef]

13. Sousa, R.L.; Einstein, H.H. Risk analysis during tunnel construction using Bayesian Networks: Porto Metro case study. Tunn. Undergr. Space Technol. 2012, 27, 86-100. [CrossRef]

14. Nieto-Morote, A.; Ruz-Vila, F. A fuzzy approach to construction project risk assessment. Int. J. Proj. Manag. 2011, 29, 220-231. [CrossRef]

15. Rezaie, K.; Amalnik, M.S.; Gereie, A.; Ostadi, B.; Shakhseniaee, M. Using extended Monte Carlo simulation method for the improvement of risk management: Consideration of relationships between uncertainties. Appl. Math. Comput. 2007, 190, 1492-1501. [CrossRef]

16. Monte Carlo Simulations: Efficiency Improvement Techniques and Statistical Considerations. Available online: https://www.aapm.org/meetings/06ss/documents/SheikhBagheriMonday.pdf (accessed on 16 October 2017).

17. Myers, D.E. Reliability and Statistics in Geotechnical Engineering. Technometrics 2005, 47, 103-104. [CrossRef]

18. Brown, E.T. Risk assessment and management in underground rock engineering-An overview. J. Rock Mech. Geotech. Eng. 2012, 4, 193-204. [CrossRef]

19. Beer, M.; Ferson, S.; Kreinovich, V. Imprecise probabilities in engineering analyses. Mech. Syst. Signal Process. 2013, 37, 4-29. [CrossRef]

20. Angelis, M.D.; Patelli, E.; Beer, M. A generalized numerical framework of imprecise probability to propagate epistemic uncertainty. In Proceedings of the International Conference on Reliable Engineering Computing, Chicago, IL, USA, 26-28 May 2014. 
21. Li, X.; Li, Y. Research on risk assessment system for water inrush in the karst tunnel construction based on GIS: Case study on the diversion tunnel groups of the Jinping II Hydropower Station. Tunn. Undergr. Space Technol. 2014, 40, 182-191. [CrossRef]

22. Choi, H.H.; Cho, H.N.; Seo, J.W. Risk Assessment Methodology for Underground Construction Projects. J. Constr. Eng. Manag. 2004, 130, 258-272. [CrossRef]

23. Fouladgar, M.M.; Yazdani-Chamzini, A.; Zavadskas, E.K. Risk evaluation of tunneling projects. Arch. Civ. Mech. Eng. 2012, 12, 1-12. [CrossRef]

24. Aven, T. The risk concept-Historical and recent development trends. Reliab. Eng. Syst. Saf. 2012, 99, 33-44. [CrossRef]

25. Ferson, S.; Ginnzburg, L.R. Different methods are needed to propage ignorance and variability. Reliab. Eng. Syst. Saf. 1996, 54, 133-144. [CrossRef]

26. Flage, R.; Aven, T.; Zio, E.; Baraldi, P. Concerns, challenges, and directions of development for the issue of representing uncertainty in risk assessment. Risk Anal. 2014, 34, 1196-1207. [CrossRef] [PubMed]

27. Dubois, D. Representation, propagation and decision issues in risk analysis under incomplete probabilistic information. Risk Anal. 2010, 30, 361-368. [CrossRef] [PubMed]

28. Terje, A.; Ortwin, R. On risk defined as an event where the outcome is uncertain. J. Risk Res. 2009, 12, 1-11.

29. Berner, C.L.; Flage, R. Creating risk management strategies based on uncertain assumptions and aspects from assumption-based planning. Reliab. Eng. Syst. Saf. 2017, 167, 10-19. [CrossRef]

30. Aven, T. Practical implications of the new risk perspectives. Reliab. Eng. Syst. Saf. 2013, 115, $136-145$. [CrossRef]

31. Dong, X.; Lu, H.; Xia, Y.; Xiong, Z. Decision-Making Model under Risk Assessment Based on Entropy. Entropy 2016, 18, 404. [CrossRef]

32. Aven, T. On the Need for Restricting the Probabilistic Analysis in Risk Assessments to Variability. Risk Anal. 2010, 30, 354-360. [CrossRef] [PubMed]

33. Li, L.; Lei, T.; Li, S.; Zhang, Q.; Xu, Z.; Shi, S.; Zhou, Z. Risk assessment of water inrush in karst tunnels and software development. Arab. J. Geosci. 2015, 8, 1843-1854. [CrossRef]

34. Yang, J.P.; Qiu, W. A measure of risk and a decision-making model based on expected utility and entropy. Eur. J. Oper. Res. 2005, 164, 792-799. [CrossRef]

35. Yang, J.; Qiu, W. Normalized Expected Utility-Entropy Measure of Risk. Entropy 2014, 16, 3590-3604. [CrossRef]

36. Aven, T.; Zio, E. Some considerations on the treatment of uncertainties in risk assessment for practical decision-making. Reliab. Eng. Syst. Saf. 2011, 96, 64-74. [CrossRef]

37. Apostolakis, G.E. How useful is quantitative risk assessment? Risk Anal. 2010, 24, 515-520. [CrossRef] [PubMed]

38. Paté-Cornell, M.E. Uncertainties in risk analysis: Six levels of treatment. Reliab. Eng. Syst. Saf. 1996, 54, 95-111. [CrossRef]

39. Tom, S.M.; Fox, C.R.; Trepel, C.; Poldrack, R.A. The neural basis of loss aversion in decision-making under risk. Science 2007, 315, 515. [CrossRef] [PubMed]

40. Karagoz, S.; Aydin, N.; Isikli, E. Decision-making in Solid Waste Management under Fuzzy Environment. In Intelligence Systems in Environmental Management: Theory and Applications; Springer International Publishing: Cham, Switzerland, 2017.

41. Gao, B.; Wu, C.; Wu, Y.; Tang, Y. Expected Utility and Entropy-Based Decision-Making Model for Large Consumers in the Smart Grid. Entropy 2015, 17, 6560-6575. [CrossRef]

42. Fischera, K. Remarks on "A measure of risk and a decision-making model based on expected utility and entropy" by Jiping Yang and Wanhua Qiu (EJOR 164 (2005), 792-799). Eur. J. Oper. Res. 2007, 182, 469-474. [CrossRef]

43. Wiecek, M.M.; Ehrgott, M.; Fadel, G.; Figueira, J.R. Multiple criteria decision making for engineering. Omega 2008, 36, 337-339. [CrossRef]

44. Kahraman, C.; Onar, S.C.; Oztaysi, B. Fuzzy Multicriteria Decision-Making: A Literature Review. Int. J. Comput. Intell. Syst. 2015, 8, 637-666. [CrossRef] 
45. Antucheviciene, J.; Kala, Z.; Marzouk, M.; Vaidogas, E.R. Solving Civil Engineering Problems by Means of Fuzzy and Stochastic MCDM Methods: Current State and Future Research. Math. Probl. Eng. 2015, 2015, 362579. [CrossRef]

46. Aven, T. Improving the foundation and practice of reliability engineering. J. Risk Reliab. 2017, 231, $295-305$. [CrossRef]

47. Aven, T. On the difference between risk as seen from the perspectives of the analysts and management. ASCE-ASME J. Risk Uncertain. Eng. Syst. Part B Mech. Eng. 2016, 2. [CrossRef]

48. Aven, T. Supplementing quantitative risk assessments with a stage addressing the risk understanding of the decision-maker. Reliab. Eng. Syst. Saf. 2016, 152, 51-57. [CrossRef]

49. Chen, B.; Wang, J.; Zhao, H.; Principe, J.C. Insights into Entropy as a Measure of Multivariate Variability. Entropy 2016, 18, 196. [CrossRef]

50. Shannon, C.E.A. A mathematical theory of communication. ACM Sigmob. Mob. Comput. Commun. Rev. 2001, 5, 3-55. [CrossRef]

51. Rao, S.S.; Cao, L. Optimum Design of Mechanical Systems Involving Interval Parameters. J. Mech. Des. 2002, 124, 465-472. [CrossRef]

52. Alola, A.A.; Tunay, M.; Alola, V. Analysis of Possibility Theory for Reasoning under Uncertainty. Int. J. Stat. Probab. 2013, 2, 171-180. [CrossRef]

53. Bae, H.R.; Grandhi, R.V.; Canfield, R.A. Epistemic uncertainty quantification techniques including evidence theory for large-scale structures. Comput. Struct. 2004, 82, 1101-1112. [CrossRef]

54. Zaman, K.; Rangavajhala, S.; Mcdonald, M.P.; Mahadevan, S. A probabilistic approach for representation of interval uncertainty. Reliab. Eng. Syst. Saf. 2011, 96, 117-130. [CrossRef]

55. Der Kiureghian, A.; Ditlevsen, O. Aleatory or epistemic? Does it matter? Struct. Saf. 2009, 31, 105-112. [CrossRef]

56. Mahadevan, S.; Rebba, R. Inclusion of model errors in reliability-based optimization. J. Mech. Des. 2006, 128, 936-944. [CrossRef]

57. Nannapaneni, S.; Mahadevan, S. Reliability analysis under epistemic uncertainty. Reliab. Eng. Syst. Saf. 2016, 155, 9-20. [CrossRef]

58. Nannapaneni, S.; Hu, Z.; Mahadevan, S. Uncertainty Quantification in Reliability Estimation with Limit State Surrogates; Springer: New York, NY, USA, 2016.

59. Mahadevan, S. Uncertainty Quantification for Decision-Making in Engineered Systems. Available online: https:/ /link.springer.com/chapter/10.1007/978-81-322-0757-3_5 (accessed on 16 October 2017).

60. Meyer, J. Representing Risk Preferences in Expected Utility Based Decision Models. In Proceedings of the Economics and Management of Risk in Agriculture and Natural Resources Meeting (SCC-76), Gulf Shores, AL, USA, 15-17 March 2007; pp. 179-190.

61. Qiu, X.; Jian, M.; Wei, F.; Li, Y. A new decision-making method based on a typical utility function. In Proceedings of the International Conference on Machine Learning and Cybernetics, Tianjin, China, 14-17 July 2013; pp. 1807-1811.

62. Brink, T.L.; Keeney, R.L.; Raiffa, H. Decisions with Multiple Objectives-Preferences and Value Tradeoffs; Cambridge University Press: Cambridge, UK; New York, NY, USA, 1993.

63. Lambropoulos, S. The use of time and cost utility for construction contract award under European Union Legislation. Build. Environ. 2007, 42, 452-463. [CrossRef]

64. Gan, Y.A.; Tian, F. Operations Research; Tsinghua University Press: Beijing, China, 2005.

65. Haaker, M.P.R.; Verheijen, P.J.T. Local and Global Sensitivity Analysis for a Reactor Design with Parameter Uncertainty. Chem. Eng. Res. Des. 2004, 82, 591-598. [CrossRef]

66. Saltelli, A.; Tarantola, S.; Chan, P.S. A Quantitative Model-Independent Method for Global Sensitivity Analysis of Model Output. Technometrics 1999, 41, 39-56. [CrossRef]

67. Liu, H.; Chen, W.; Sudjianto, A. Relative Entropy Based Method for Probabilistic Sensitivity Analysis in Engineering Design. J. Mech. Des. 2006, 128, 326-336. [CrossRef]

68. Helton, J.C.; Johnson, J.D.; Sallaberry, C.J.; Storlie, C.B. Survey of sampling-based methods for uncertainty and sensitivity analysis. Reliab. Eng. Syst. Saf. 2006, 91, 1175-1209. [CrossRef]

69. Tang, Z.; Lu, Z.; Pan, W.; Zhang, F. An entropy-based global sensitivity analysis for the structures with both fuzzy variables and random variables. Proc. Inst. Mech. Eng. Part C J. Mech. Eng. Sci. 2013, 227, 195-212. 
70. Borgonovo, E.; Plischke, E. Sensitivity analysis: A review of recent advances. Eur. J. Oper. Res. 2016, 248, 869-887. [CrossRef]

71. ISO 31000:2009 Risk Management-Principles and Guidelines (Text). Available online: https:/ / www.iso. org/standard/43170.html (accessed on 16 October 2017).

72. Li, S.C.; Zhou, Z.Q.; Ye, Z.H.; Li, L.P.; Zhang, Q.Q.; Xu, Z.H. Comprehensive geophysical prediction and treatment measures of karst caves in deep buried tunnel. J. Appl. Geophys. 2015, 116, 247-257. [CrossRef] 